\title{
Article \\ Artificial Intelligence Applications in Military Systems and Their Influence on Sense of Security of Citizens
}

\author{
Marta Bistron *(D) and Zbigniew Piotrowski \\ Faculty of Electronics, Military University of Technology, 00-908 Warsaw, Poland; \\ zbigniew.piotrowski@wat.edu.pl \\ * Correspondence: marta.bistron@wat.edu.pl
}

check for updates

Citation: Bistron, M.; Piotrowski, Z. Artificial Intelligence Applications in Military Systems and Their Influence on Sense of Security of Citizens. Electronics 2021, 10, 871. https:// doi.org/10.3390/electronics10070871

Academic Editors: Imre J. Rudas and Jun Liu

Received: 16 February 2021

Accepted: 2 April 2021

Published: 6 April 2021

Publisher's Note: MDPI stays neutral with regard to jurisdictional claims in published maps and institutional affiliations.

Copyright: (C) 2021 by the authors Licensee MDPI, Basel, Switzerland. This article is an open access article distributed under the terms and conditions of the Creative Commons Attribution (CC BY) license (https:// creativecommons.org/licenses/by/ $4.0 /)$.

\begin{abstract}
The paper presents an overview of current and expected prospects for the development of artificial intelligence algorithms, especially in military applications, and conducted research regarding applications in the area of civilian life. Attention was paid mainly to the use of AI algorithms in cybersecurity, object detection, military logistics and robotics. It discusses the problems connected with the present solutions and how artificial intelligence can help solve them. It briefly presents also mathematical structures and descriptions for ART, CNN and SVM networks as well as ExpectationMaximization and Gaussian Mixture Model algorithms that are used in solving of discussed problems. The third chapter discusses the attitude of society towards the use of neural network algorithms in military applications. The basic problems related to ethics in the application of artificial intelligence and issues of responsibility for errors made by autonomous systems are discussed.
\end{abstract}

Keywords: neural networks; artificial intelligence; $\mathrm{AI}$ in military; $\mathrm{CNN}$; social robots

\section{Introduction}

One of the main pillars determining the position of a state in the international arena is its military potential. As defined by the U.S. Department of Defense, military capability means [1] "the ability to achieve a specified wartime objective (win a war or battle, destroy a target set)." Military capability is determined by structure, modernization, readiness and sustainability. The level of modernization depends mainly on technical sophistication, weapon systems and equipment.

A typical war known from the Second World War is slowly fading into oblivion and goes into cyberspace. As research shows [2] hacker attacks on both private companies and government institutions have become a common phenomenon. According to researchers [3,4], artificial intelligence (AI) and innovative automatic systems will become an inseparable element of future armed conflicts.

Most modern AI algorithms require large amount of data [5] for example AI algorithms to natural language processing [6]. They can work better, faster and more efficient, but they cannot work well without access to large databases. Access to extensive data sources and the increasing computing power of machines have enabled the development of this field of science. Nowadays, interest in using neural networks is still growing, which can be observed by analyzing scientific publications on various topics from the last few years-development of ITS (Intelligent Transport Systems) [7,8], prediction and evaluation of atmospheric phenomena [9-11], distinguish information tweets (containing relevant facts) from non-information ones (containing rumors or non-detailed information) [12] and predicting dynamic FX markets [13] and the real estate market [14]. In military sector, AI algorithms can be used, among others, for speech recognition systems [15] or object detection and recognition [16].

Artificial intelligence has a wide range of applications, resulting in its enormous and multi-faceted impact on society. In recent years AI hast taken part in creating new standards of social behavior, people-to-people contacts and even politics and functioning 
of state, what the authors write about in [17-19]. New technologies give hope but also inspire fear, which is discussed in more detail later in this paper. The rest of the paper is organized as follows: Chapter 2 presents used methodology; Chapter 3 discusses examples of applications based on the use of artificial intelligence in military; Chapter 4 is dedicated to the impact of using these algorithms in military on state politics, state defense and sense of security of citizens; Chapter 5 shows conclusions relating to the overview.

\section{Methodology}

Firstly, selected examples of artificial intelligence algorithms used in military systems are presented. Said examples are related to areas of the army particularly important in terms of ensuring the proper functioning and the security of the state and all citizens and play a crucial role in conducting modern combat activities on the battlefield. The used taxonomy (showed in detailed way in Figure 1) presents the overview of literature coming from the type of military applications or area of applications to the different algorithms of artificial intelligence used to solve this problem. All areas and specific algorithms are shortly described in order to better understanding of the development of AI in military.

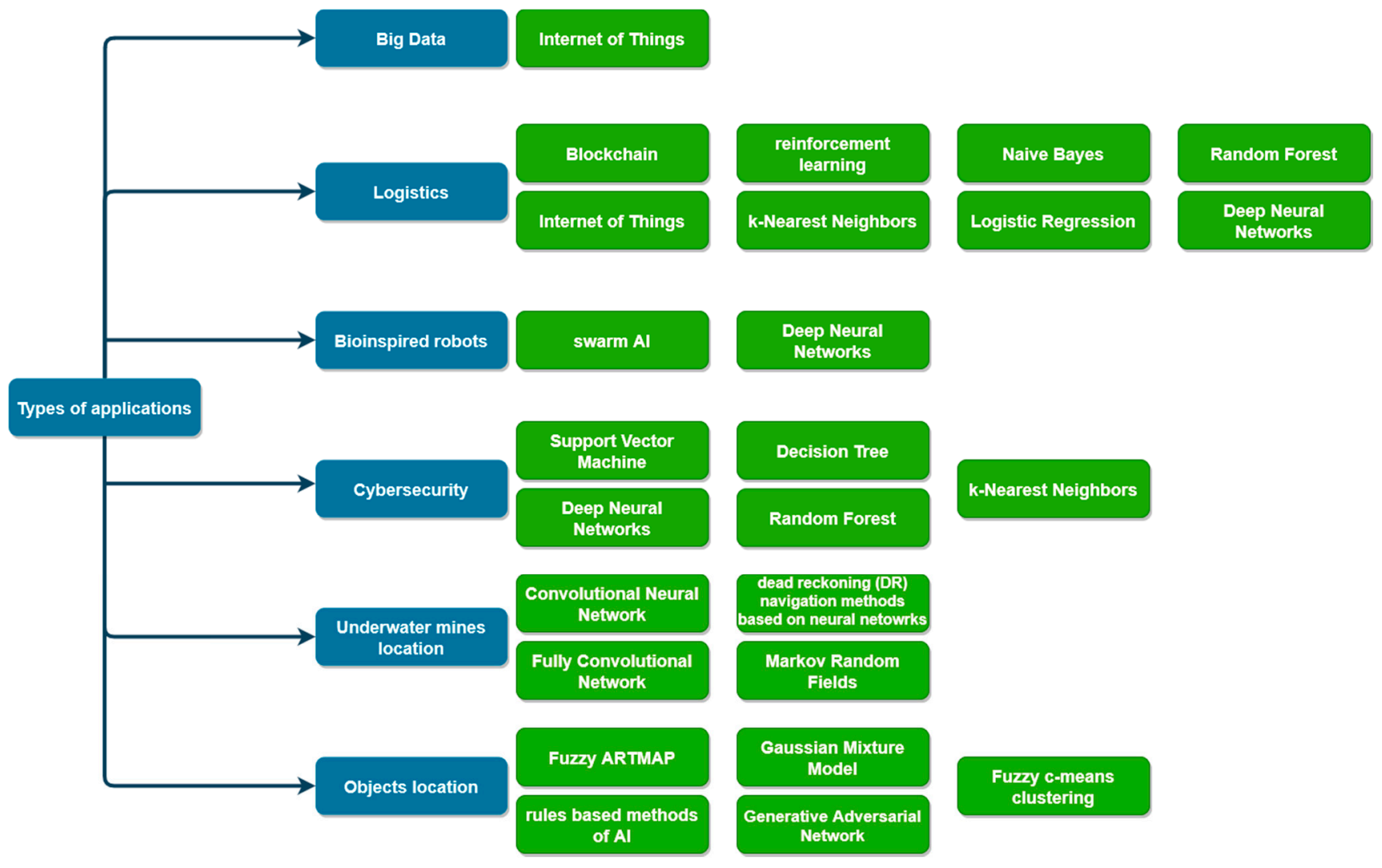

Figure 1. Taxonomy proposed in the overview of military applications.

With reference to the described military applications, an analysis of the main concerns of the society regarding the development of $\mathrm{AI}$ in the context of ethics and social behavior was performed. The surveys conducted in 2011 and 2019 on the attitudes of citizens from various social groups to the development of artificial intelligence algorithms in various areas and applications were compared.

\section{Practical Using of Neural Networks in Military Applications}

Artificial neural networks in military applications have great potential in every field; they can provide support during land, sea, air and information warfare. Artificial intelligence finds military applications in logistics, transport, armed attack analysis and in 
communication, which was presented in the report [20]. The existence of a high demand for applications using AI in the defense sector is confirmed by the AIE (Artificial Intelligence Exploration) program launched by DARPA (Defense Advanced Research Projects Agency) in July 2018 [21], which is a key element of the organization's investment strategy focused on providing advantage to the United States in this area of technology. Moreover, the European Defence Agency supports the use of artificial intelligence in the field of defense, especially for tasks related to the processing of large amounts of data [22]. The following chapter provides some examples of the use of AI technology in military applications.

\subsection{Application of Neural Networks in Object Location}

Classic methods of location at sea include among others the use of various types of radar stations, air patrols, maritime patrols, remotely controlled drones or satellites, e.g., CleanSeaNet - the European satellite object and pollution detection service, developed and monitored by EMSA [23]. In recent years, the automatic identification system (AIS) has also become very popular. The system provides a lot of information about marine traffic; however, due to the large amount of processed data, it is not always effective. Instead, various machine learning approaches are used to monitor and inform about any anomaly - the movement that deviates from established standards.

One of the methods used in AISs is Fuzzy ARTMAP [24]. It is an architecture that combines fuzzy logic elements and Adaptive Resonance Theory (ART) neural networks. By default, ART uses unsupervised learning technique. The algorithm of the network operation consists in maintaining readiness to learn new patterns while preventing the rejection or modification of previously learned ones [25]. The system must be able to maintain stability when facing non-significant events and the ability to update on significant events. The basic ART network consists of two layers and a reset module, which are shown in Figure 2. The first layer, called the comparison field, receives normalized input data, processes it and transfers it to the second layer with appropriate weights. The second layer, otherwise the recognition field is a competitive layer according to the WTA principle"winner takes all" [26], in which the unit with the best match (the highest product of the input vector and weight) becomes a candidate for learning a new pattern; the other units are ignored. The reset module decides whether a new unit can learn a pattern based on its similarity to the prototype vector; this is called the vigilance test.

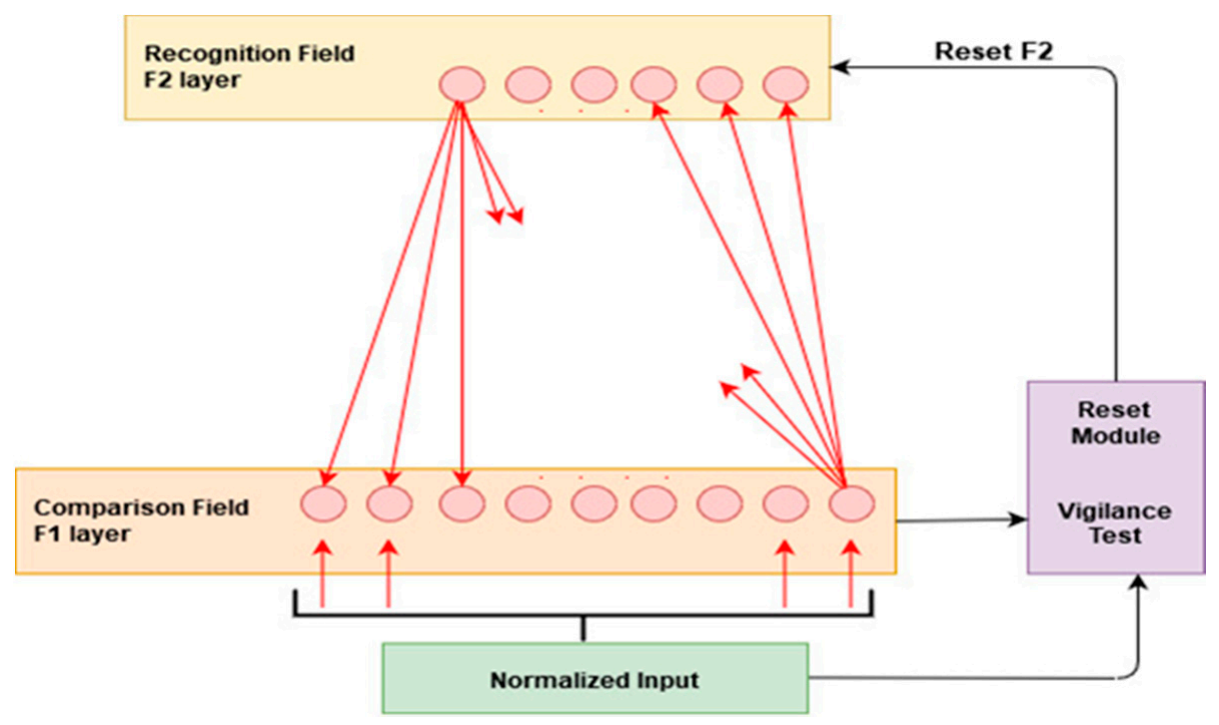

Figure 2. Structure of the Adaptive Resonance Theory (ART) network with emphasis on existing layers and mechanisms [25]. 
The authors modified the basic algorithm to obtain greater speed and efficiency of training, which allows it to be adapted in real time and in interactive conditions (the operator supports model training).

Other solution of AIS was presented in [27]. Authors proposed using the old-fashioned artificial intelligence method of data integrity assessment based on set of rules. The work was developed in cooperation with representatives of French military units-officers of the French Navy and cadets of the French naval academy.

In [28], authors present another method of grouping data based on similarityGaussian Mixture Model (GMM). Most of the data can be modelled using the Gaussian distribution. The idea of this model is to assume that the data for grouping comes from different Gaussian distributions, so the data set can be modeled as a mixture of different Gaussian distributions. The Gaussian distribution is described as follows [29]:

$$
f\left(x, \mu, \sigma^{2}\right)=\frac{1}{\sigma \sqrt{2 \pi}} e^{-\frac{1}{2}\left(\frac{x-\mu}{\sigma}\right)^{2}},
$$

where $\mu$ is a location parameter, equal to the distribution mean and 6 is the standard deviation.

According to the method described in [30], it is assumed that there are $K$ units (clusters) with estimated values of $\mu$ and 6 parameters, for which the probability density function is defined as a linear probability density function of all distributions:

$$
p(X)=\sum_{k=1}^{K} \mu_{k} G\left(X \mid \mu_{k}, \Sigma_{k}\right)
$$

where

$\Sigma$-covariance matrix;

$G\left(X \mid \mu_{k}, \Sigma_{k}\right)$ - the probability density function of a Gaussian Distribution.

Defining an example variable ${ }_{k}(X)=p(k \mid X)$ in accordance with the Bayes' theorem that will be used in further calculations:

$$
\mathrm{Q}_{k}(X)=p(k \mid X)=\frac{p(X \mid k) p(k)}{\sum_{k=1}^{K} p(k) p(X \mid k)}=\frac{p(X \mid k) \pi_{k}}{\sum_{k=1}^{K} \pi_{k} p(X \mid k)}
$$

For the probability function to be maximum, its derivative of $p(X \mid \mu, \Sigma, \pi)$ with respect to $\pi, \Sigma, \mu$ should equal zero. After substitution $Q_{k}(X)$ in equations, the following are obtained:

$$
\begin{gathered}
\mu_{k}=\frac{\sum_{n=1}^{N} \mathrm{o}_{k}\left(x_{n}\right) x_{n}}{\sum_{n=1}^{N} \varphi_{k}\left(x_{n}\right)}, \\
\Sigma_{k}=\frac{\sum_{n=1}^{N} Q_{k}\left(x_{n}\right)\left(x_{n}-\mu_{k}\right)\left(x_{n}-\mu_{k}\right)^{T}}{\sum_{n=1}^{N} \varphi_{k}\left(x_{n}\right)} \\
\pi_{k}=\frac{1}{N} \sum_{n=1}^{N} \varphi_{k}\left(x_{n}\right) x_{n}
\end{gathered}
$$

where the sum $\sum_{n=1}^{N} Q_{k}\left(x_{n}\right)$ is the total number of sampling points in the $k$-th set.

Parameters cannot be estimated in closed form; that is why the iterative ExpectationMaximization algorithm is used together with the GMM. This is a frequently used method [31] that helps identify the maximum probability estimates when the data is incomplete or contains hidden variables.

The crucial issue in object detection problem is the separation of moving and stationary targets. Synthetic aperture radars (SAR) are very often used for this purpose in view of their capability to removing the ambiguity stemming from inevitable moving targets in stationary scene imaging and suppressing clutter in moving target imaging. In [32] the author proposed using a novel solution - shuffle GAN (generative adversarial networks) with autoencoder separation method to separate the moving and stationary targets in SAR 
imagery. One of the biggest advantages of this method is working in a totally unsupervised way, which allows to train the model without the dataset containing mixed and separated SAR images. The idea of GAN is a "combat" between two networks working recursively. The first of them-generator-generates new data, and the second one-discriminatorworks in slightly similar way to the classifier. It assesses results of work of the generator. The whole training process is repeated as long as the discriminator will evaluate the results of the generator as true (it is not possible to distinguish produced images from original images) [33].

Image segmentation relies on partitioning an image into multiple segments that are related to various groups of objects, for example, neutral objects and threats. There are a lot of different methods of segmentation: thresholding, region of interest based, clustering, compression-based, Histogram-based, etc. Clustering is a method of grouping of unlabeled data that determines a feature vector for each pixel of the image and uses a similarity metric for clustering vectors that have similar features. One of the popular methods used for this purpose is fuzzy c-means clustering (FCM) developed by J.C. Dunn in 1973 [34]. The idea of the algorithm is very similar to k-means [35] and based on computing the centroid for each cluster and coefficients of being in the clusters. The procedure is repeated until the algorithm has converged, i.e., until the change of coefficients between two iterations is no more than threshold. Authors in [36] proposed using an approach based on extracting texture and geometry structure features to detect objects like planes, tanks and vehicles in natural background using FCM. Object detection and recognition is a very important area of the modern warfare. The future research in this domain should be focused on achieving better results by electronic armed forces in

- $\quad$ Automatization of the localization process and increase in the accuracy of the localization;

- Operation of location systems in conditions of targeted environmental disturbances;

- Achieving operational reliability of location modules based on distributed networks.

\subsection{Location of Underwater Mines Using Deep Convolutional Neural Network}

Underwater mines pose a very high threat to passing ships. Various types of mine countermeasures are used to localize and neutralize the threat [37,38]. The purpose of future countermeasures is to ensure unrestricted freedom of movement for naval forces and to rapidly remove mines when needed. For this goal, Unmanned Airborne Vehicle (UAV) and Unmanned Undersea Vehicle (UUV), also known as autonomous underwater vehicles (AUV), are being developed. UAVs are mainly used by the armed forces for observation and reconnaissance, which is why they are usually equipped with observation equipment in the form of optoelectronic heads. Armed drones designed to perform combat operations are often referred to as Unmanned combat air vehicles (UCAVs). UUVs, sometimes known as underwater drones, are equipped with sonars that create seabed maps based on the collected data. Such vehicles are developed, among others, by the Monterey Bay Aquarium Research Institute (MBARI) [39], which uses them for collecting information from underwater areas. AUVs create and accumulate large amounts of photos, that must then be classified to distinguish mines from other objects. Deep convolutional neural networks can be used for this purpose.

A neural network consists of an input layer, output layer and optionally also hidden layers (in Figure 3). Each neural network that has at least one hidden layer is called deep neural network DNN. 


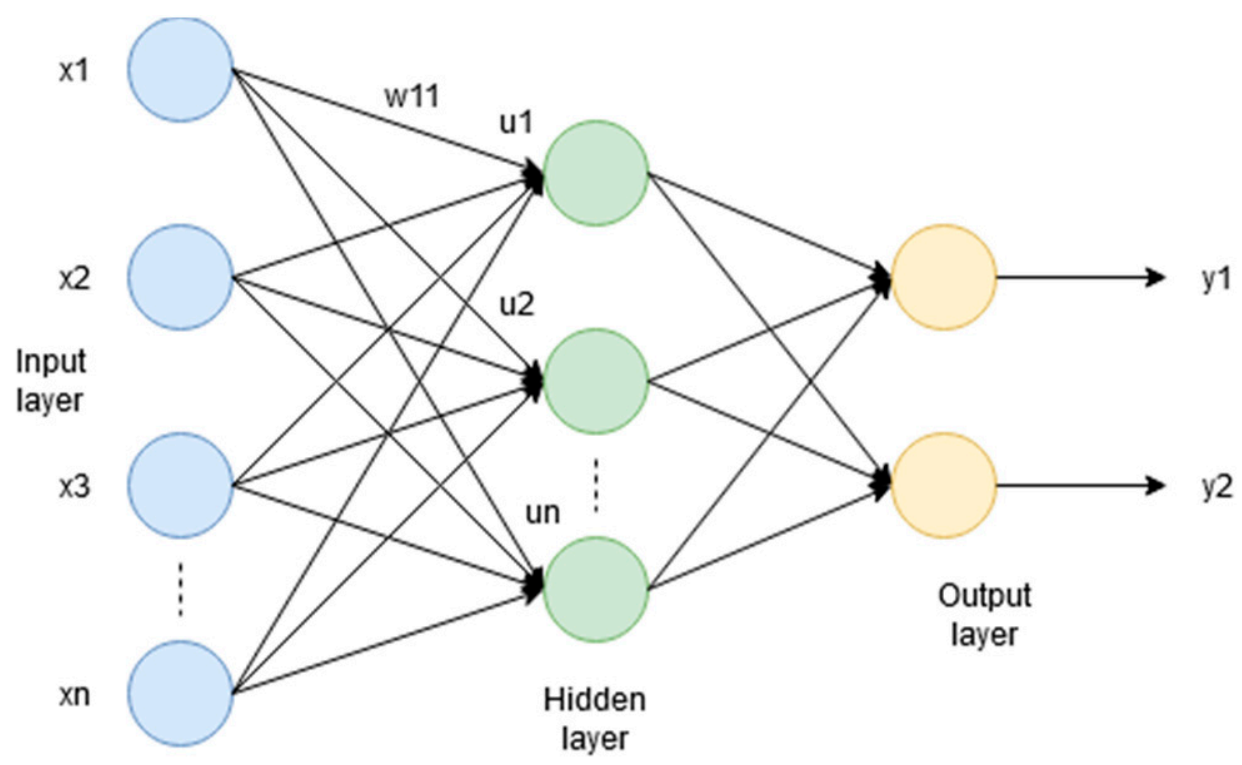

Figure 3. A three-layers deep neural network with one hidden layer.

In [40], authors proposed an autonomous underwater vehicle with side scan sonar (SSS). The sensor carries out image segmentation using convolutional neural networks $\mathrm{CNN}(\mathrm{CNN})$. It is one of the deep networks variants often used to process digital images. The main advantage of the convolutional network compared to traditional algorithms is that there is no need to perform feature extraction. The network consists of a convolution base and a classifier built of the so-called fully connected layers (FC). The most important element of the convolution base are the convolution layers, which, using sets of filters with different sizes of filter mask - firstly, bigger filters are used that filter each channel of the input image to extract features, thus creating feature maps whose dimensions are smaller and smaller, while the depth gets bigger. Mathematically, convolution operation is presented as follows [41]:

$$
y(n)=x(n) \otimes h(n)=\sum_{k=-\infty}^{\infty} x(k) h(n-k)
$$

The scheme of the convolution layer operation was shown in Figure 4.

Solution proposed by authors is a Fully Convolutional Network (FCN). In this method convolution operations are used in the fully connected layer. For better results also Markov random fields (MRF) were used. The combination of the methods allowed to obtain an overall accuracy of $90 \%$.

Authors in [42] presented a solution of AUV with dead-reckoning (DR) navigation method based on neural networks, called NN-DR which is perfect for rapidly changing conditions. The training was carried out on a network consisting of 3 hidden layers because of limited computational ability and energy of AUVs.

Location underwater mines is a one of the crucial area of object detection in military applications affecting on the sense of security both of civilians and military. The future research in this domain should be concentrated on the following:

- Effective and fast location of underwater mines in real time;

- Increasing the reliability in detecting and distinguishing between hazardous and neutral objects;

- Effective cooperation of detection systems with systems that neutralize the threat. 


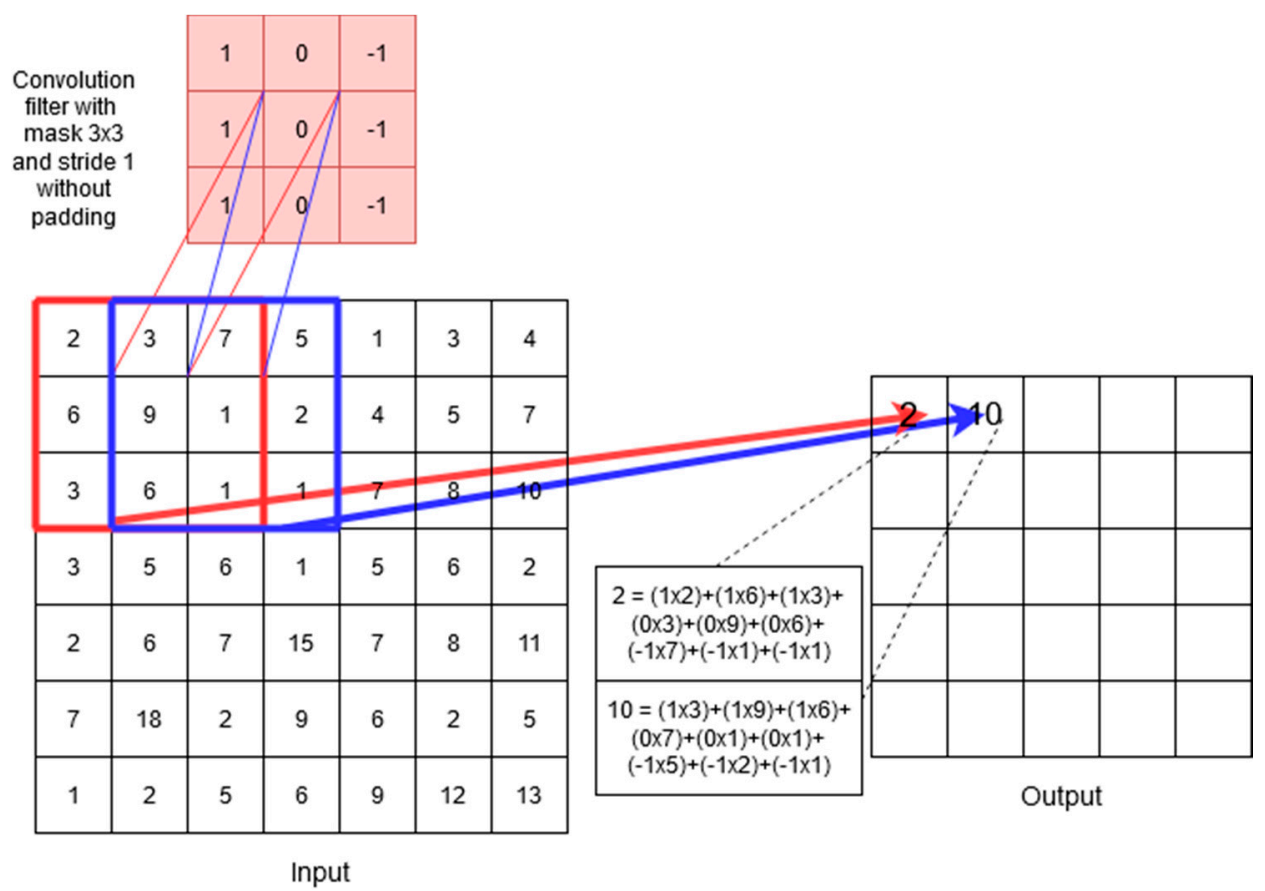

Figure 4. The idea of the convolution layer operation.

\subsection{Application of Neural Networks in Cybersecurity}

Hackers' attacks are becoming more and more common and dangerous with every year. As reports and studies show [43], both commercial companies as well as public, defense and government institutions of various countries are threatened by them. Incident detection is carried out via the IDS (intrusion detection system), that analyses network traffic, classifies it as intrusive or normal and in the event of danger sends a notification [44]. The normal network traffic often has a similar signature to attacks, making classification difficult. In addition, the method is often slow and expensive, which gave rise to the idea of using artificial intelligence algorithms for this purpose. One of the techniques that is being tested for IDS support is the Support Vector Machine (SVM) [45].

SVM is an algorithm that aims to find a hyperplane in the $\mathrm{N}$-dimensional space that clearly classifies (separates) data points. There are many such hyperplanes, but the algorithm looks for the one with the maximum margin, i.e., the maximum distance between points of individual classes that provides better generalization capacity and greater resistance to overlearning. The hyperplanes can have different shapes as was shown in Figure 5.
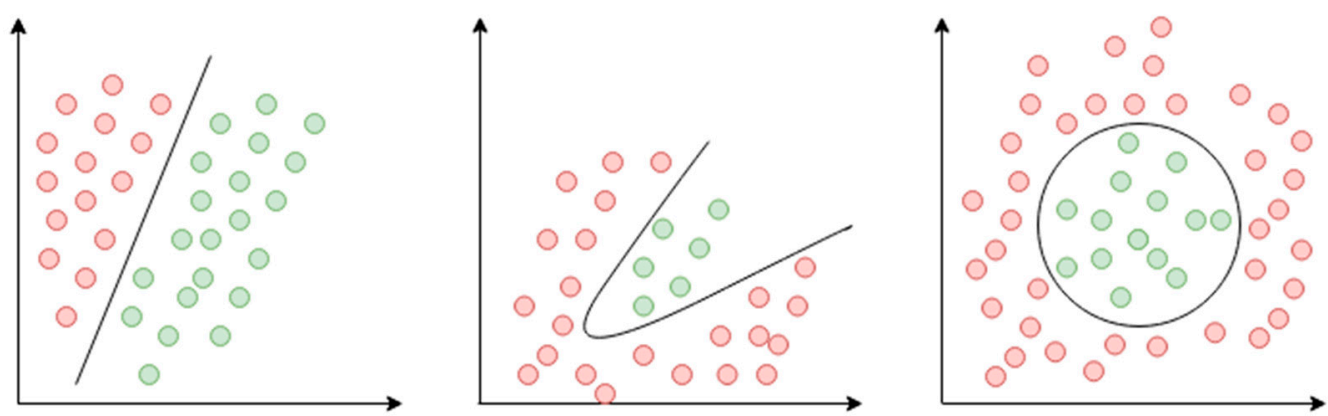

Figure 5. Different types of separating hyperplanes. 
A linear hyperplane is described by a linear equation [46] that maximizes the distance between the extreme points of both classes:

$$
y(x)=w x+b=0,
$$

$x$-vector $x=\left(x 1, x 2, \ldots, x_{n}\right)$

$w$-vector $w=\left(w 1, w 2, \ldots, w_{n}\right)$;

$b$-bias.

The hyperplane equation as a classifier assigns points to the appropriate classes $(+1$ or -1 ) according to the equations [46]:

$$
\begin{array}{ll}
w x_{i}+b \geq 0, & h\left(x_{i}\right)=+1, \\
w x_{i}+b \leq 0, & h\left(x_{i}\right)=-1,
\end{array}
$$

The purpose of the learning is to maximize the separation margin $\frac{2}{\|w\|}$, which means that the following condition is fulfilled:

$$
\max \left(\frac{2}{\|w\|}\right) \rightarrow \min \left(\frac{\|w\|}{2}\right) \rightarrow \min \left(\frac{1}{2}\left\|w^{2}\right\|\right),
$$

Each SVM network can distinguish only two classes. There are two techniques for solving multiclass problems: one-against-all (there are as many 2-classes classifiers as there are classes) and one-against-one there are as many classifiers as there are pairs of classes) [47].

Authors in [48] presented a comparison of different AI algorithms that can be used in intrusion detection systems. They tested machine learning classification algorithms such as Decision Tree, k-Nearest Neighbors, Random Forest and SVM and also two models of neural networks with the same architecture and different types of optimizers-Adam optimizer and stochastic gradient descent [49]. Feature selection was performed with using a Support Vector Classifier with a linear kernel as the estimator and forward feature selection with cross validation to rank the features. Proposed system based on anomaly detection does not only distinguish network traffic packets signatures but to also determines whether a network intrusion was obfuscated.

Nowadays, a large percentage of military operations has been transferred to cyber space. One of the key factors determining the success of a military mission was ensuring the security and secrecy of combat data. The issues that should be developed and improved in this domain in the nearest future are the following:

- Improving the operation of systems securing access to key data-authorization and authentication modules;

- Support for systems identifying unauthorized access to data in real time.

\subsection{Bioinspired AI Robots on the Battlefield}

One of the main goals of modern technology on the battlefield is to protect the health and lives of soldiers. A solution often proposed in this regard is to bring the machines onto the battlefield. The world leader in the field of mobile robots is the American company Boston Dynamics [50]. The robots can move independently, detect and avoid obstacles, follow a predetermined route, as well as recognize and respond to voice messages coming from the environment. Enrico Guizzo in [51] describes his impressions of the visit to the Boston Dynamics headquarters and presents some of their solutions-Spot and Atlas.

Spot is a nimble quadruped which can move over almost any terrain. On the front, back and sides of the robot, there are sensors with cameras that allow you to use the SLAM (simultaneous localization and mapping) navigation method. SLAM algorithms are very often employed in problems combining the need to update the map of an unknown environment while tracking a moving object, including objects localization [52], pedestrians recognition [53] or localization unmanned aerial vehicles position [54]. Spot behaves 
completely autonomously or can be controlled remotely, while retaining a great deal of autonomy. The robot is presented in Figure 6.

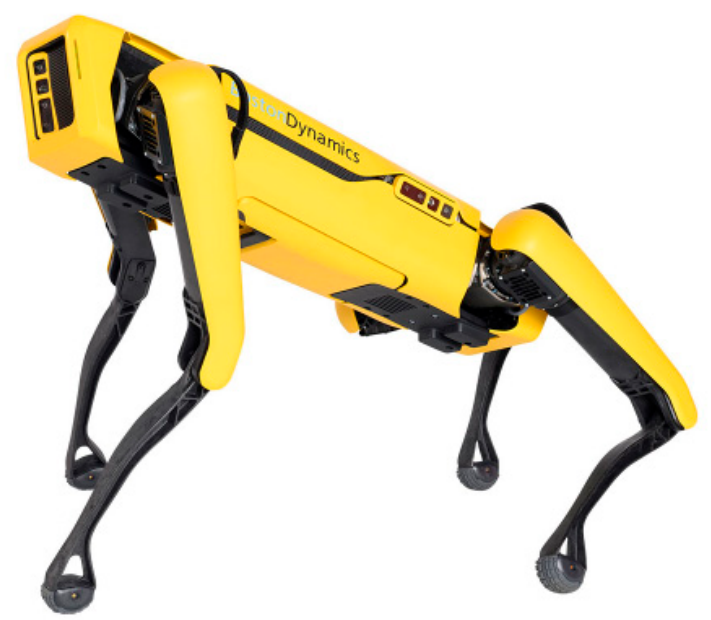

(a)

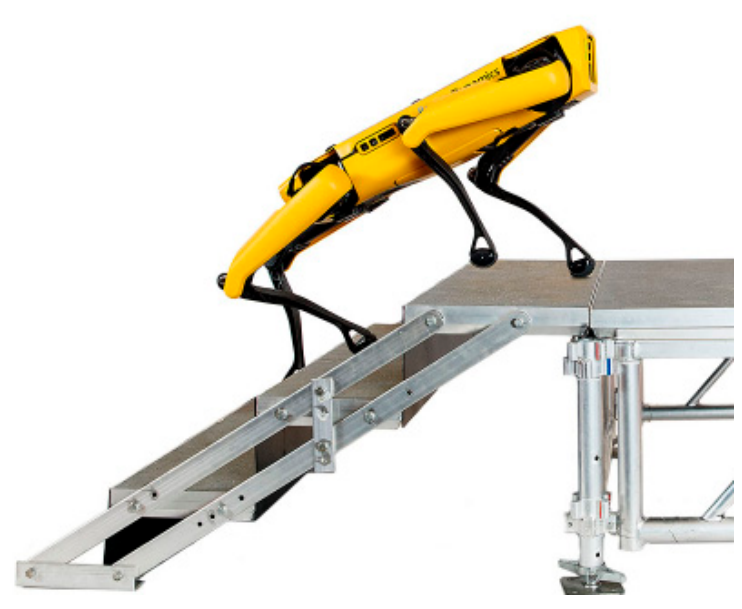

(b)

Figure 6. Spot: (a) overall look, (b) going up the stairs [55].

Atlas is a 150-cm-tall humanoid. The control software uses mathematical models of the robot's physics and the integration of its body with the environment, so that the movements performed are as natural as possible, inspired by the behavior of athletes. The first version of the robot was developed as part of a competition DARPA Robotics Challenge in 2015. Atlas was presented in Figure 7.

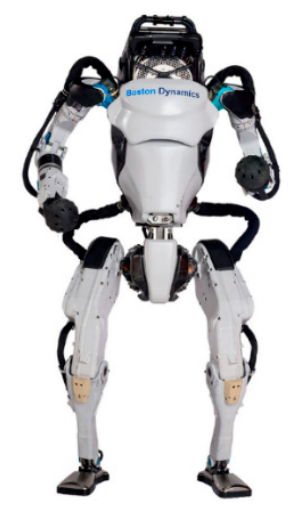

(a)

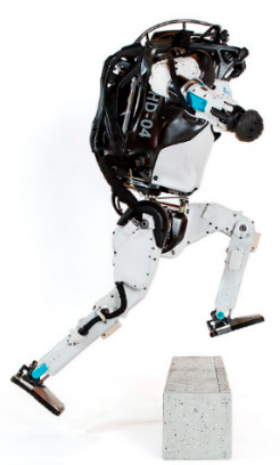

(b)

Figure 7. Atlas: (a) overall look, (b) jumping over an obstacle [55].

Even higher results on the battlefield can be achieved with the cooperation of humanoid robots, e.g., with the use of Swarm AI, as shown in [56] in the example of cleaning robots.

Using bioinspired robots in military operations can become the new standard of warfare in a short time. Robots are resistant to fatigue, lack of food and water and extreme weather conditions, but their proper functioning can be easily disturbed by hacker attacks. The main goal of future research related to this area should be ensuring reliability and resistance to hostile interference in the software of robot.

\subsection{AI Applications for Military Logistics}

Logistics, distribution and supply chain are parts of a very sophisticated and advanced process that refers to the movement of products or services to a designated location at an 
agreed time. The history of logistics is inextricably linked with military. Already, ancient Romans organized efficient logistic systems to supply legions [57].

Currently, logistics especially in military domain includes many different functions related to the processing of large amounts of data and making of decisions related to transport, delivery and communication, supporting combat units and many others. Organizing an efficient supply chain is very important both in times of peace and war. In [58], authors proposed a method of military logistics management based on the Internet of Things (IoT) that allows to shorten the logistical response time and improve the speed of actions. Authors in [59] noted an important issue of ensuring safety and reliability of supply chain which is crucial operational capability of military forces. They proposed new solution Military Supply Chain Cyber Implications Model (M-SCCIM) which combines logistic and cybersecurity. The presented model uses the newest technologies such as Internet of Things (IoT) and smart contracts. Smart contracts are "pieces of software that represent a business arrangement and execute themselves automatically under predetermined circumstances" [60]. In implementation of smart contracts, some blockchain technologies which ensure decentralization, persistency, anonymity and auditability are used. In military supply chains, smart contracts can be responsible for checking product flows throughout the supply chain or ensuring the integrity of the chain. Using IoT devices in supply chains allows for better tracking movement of goods (also tracking speed and traffic flow of movement) that makes easier other administrative actions associated to supply chain. However, some properties of IoT structure that are beneficial in commercial environment can be big challenges to implement in military network architectures, which was described in [61]. The military needs a weapon, repair parts, fuel and a lot of other equipment; that is why one of the most important elements of military logistics is a process of management of supply chain. Authors in [62] present a technology to control a supply chain that ensures speed and safety and maximizes the military and economic benefits. Important elements of each supply chain are data analysis and decision-making process. Nowadays, a reinforcement learning is a very common technique supporting decisionmaking, also in the pre-war planning stage [63] which includes planning supplies to the battlefield and other issues related to military logistics. The reinforcement learning is one of the three main types of machine learning approach. In this approach, the user does not prepare a large training dataset to learn the model, but he uses the environment that allows to collect learning data automatically. The idea of training is interactions of agents with the environment in order to maximize the reward returned by the environment [64]. The idea of the reinforcement learning was presented in Figure 8.

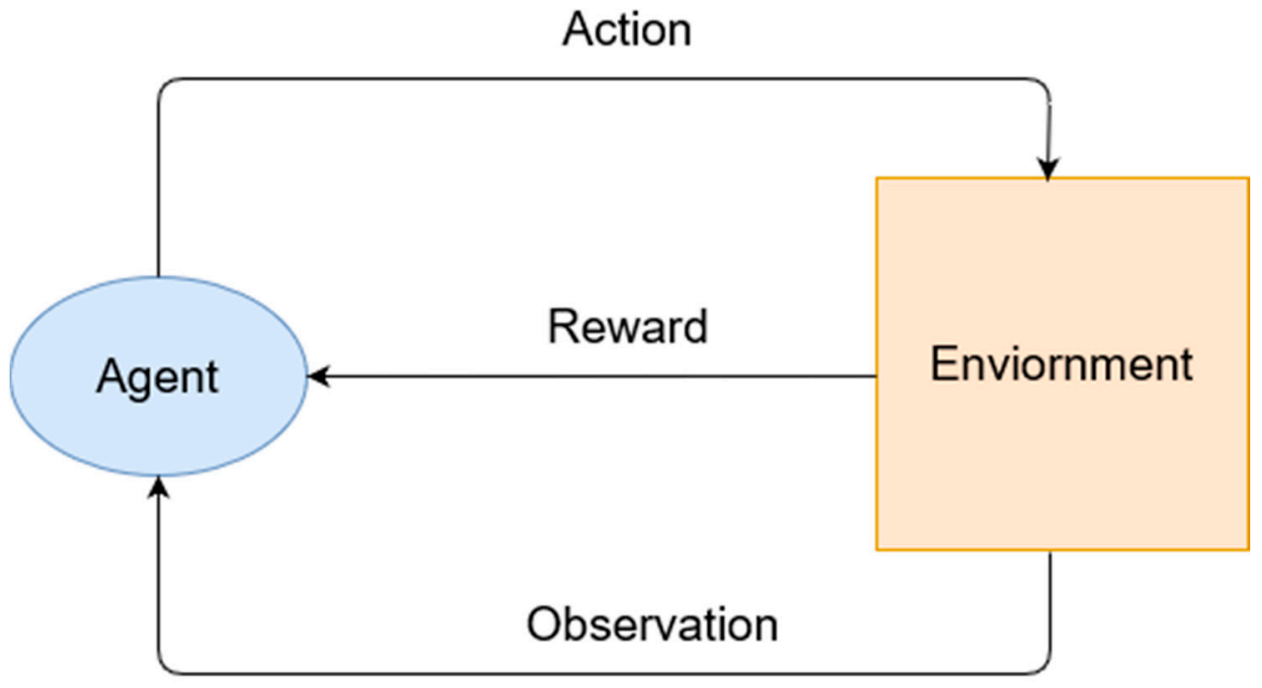

Figure 8. Reinforcement learning. 
Another approach to supply chain management was presented in [65]. Authors compared artificial neural network (ANN) and machine learning algorithms like k-Nearest Neighbors, Logistic Regression, Random Forest and Naive Bayes in solving the problem of prediction of availability and possible reorder level of military logistics in an example of ensuring the availability of petroleum products.

Another important issue in the field of military logistics is efficient and quick organization of medical aid. It is planned that artificial intelligence will be a significant help in monitoring, diagnosing and segregating the wounded on the battlefield, to provide help to all those in need with limited resources. Charles River Analytics [66] is working on a semi-automatic support software for doctors, used when the evacuation of a soldier from the battlefield is not possible. The application called Automated Ruggedized Combat Casualty Care (ARC3) is implemented on behalf of the U.S. Army's Telemedicine \& Advanced Technology Research Center (TATRC). This system is part of the strategy of trauma care on the battlefield, known as Tactical Combat Casualty Care (TCCC) [67].

Over the years, logistics has been one of the crucial parts of the military that influences the course of hostilities. In coming years, research in this area should be focused on the following:

- $\quad$ Acceleration of logistics processes, in particular in the supply chain, by applying deep learning algorithms that enable the processing of large amounts of data;

- Improving the timeliness of logistics deliveries;

- Cooperation of logistic data analysis systems with systems ensuring data security in order to ensure reliability and protection against diversionary activities.

\subsection{Big Data in Milatry Data Processing and Modeling}

All previously described AI solutions very often require big amounts of digital data. Its storage, transfer, analysis and visualization generate a lot of problems related to restricted computational power capabilities even for military hardware. Remedies for this problem can be found by using innovative modern architectures including Big Data solutions. In order to better understanding Big Data methodologies, techniques and their potential influence the development of the defense domain; in September 2016, the European Defence Agency (EDA) launched the "Big Data in Defence Modelling and Simulation" (BIDADEMS) [68]. According to recommendations from research, future modelling and simulations military applications should be designed using Cloud Computing. It also seems necessary to focus on education of analysts on new data analytics techniques and providing developers with Big Data tools when developing future models. The study results have led to a new research project (Modelling and Simulation Methodologies for Operations Research - MODSIMMET) analyzing very complex scenarios like hybrid warfare supported by Big Data and Artificial Intelligence.

Authors in [69] analyzed the application of military big data in equipment quality information management. They showed how the more effective flow of equipment quality information in the process could improve the management of information in comparison to scattered systems based on information from people. Other research presented in [70] showed possibilities of optimization of the education model in the military campus using Big Data systems to store and analyze students and teachers data. The proposed system is based on using Internet of Things and directed acyclic graph (DAG) to data processing. The aim of the described solution is the optimization of decision-making processes. The research highlights the reforming trend in education under the "military reform of Chinese characteristics" [71].

The need to process very large amounts of data requires the use of Big Data solutions and data collection in cloud systems. The most important thing that should be improved and developed in this area is ensuring the security of processed data. Another crucial issue is concentrating on introducing cloud solutions and cooperation between systems in each area of military operations. 


\section{Impact of Using Artificial Intelligence in Military on Society}

As the examples show, the neural network applications can be very useful and effective also in the military sector. Actions that have been carried out by people in recent years are now fully automated. Algorithms decide what is good and what is bad, what is safe and what is dangerous, when we should react and when we should wait. The problem is even more important when we talk about AI applications in the military, because their decisions will affect the lives of all citizens. Can people feel safe when machines decide upon their lives? Some people are ready to fully trust the machine and nominate it to presidential election. This happened in Russia in 2017 when forty thousand Russians nominated a piece of AI software called "Alice" to stand against Vladimir Putin in the 2018 election. The virtual assistant created by Yandex could work 24/7 and used only logic to make decisions without emotions and seeking personal advantages [72]. A similar situation happened in Tokyo where a machine named "Michihito Matsuda" placed third in the election of mayor and in New Zealand where "Sam" was created—the world's first Virtual Politician [73]. "Sam" was designed to run in the 2020 general election to analyze everyone's opinions and to promote better policy for every citizen, but some people are still very skeptical and have a lot of fears related to AI.

\subsection{Explainable Artificial Intelligence}

Explainable Artificial Intelligence (XAI) is a new trend that relates to the methods and techniques of applying artificial intelligence technology, so that the obtained solution results are understandable to the average person [74,75]. As the authors say in [76], this "research field holds substantial promise for improving trust and transparency of AI-based systems."

The Centre for the Governance of AI (GovAI), part of the Future of Humanity Institute at the University of Oxford [77], is an organization that supports society in reaping the benefits and risk management of artificial intelligence. They conduct extensive research on important and neglected issues in AI management using political science, international relations, computer science, economics, law, and philosophy. Below is a brief summary of the surveys conducted by GovAI in 2011 [78] and 2019 [79] regarding the public's attitude towards AI.

As stated in research carried out in 2011, according to respondents, artificial intelligence will reach the level of human intelligence at $50 \%$ around 2050 and $90 \%$ around 2150 . Organizations from the area of industry, the military and academic centers will have the biggest contribution to development. In the case of the question about the probability of positive and negative effects of developing human-level artificial intelligence, the highest probability was indicated for the answer "extremely bad". However, the answer "extremely good" came second which proves the presence of both extreme threats and benefits of AI. The survey results are presented in Figure 9.

According to research carried out in 2019, 41\% of respondents support or strongly support the development of artificial intelligence, while $21 \%$ are somewhat or definitely against it. Much greater support (57\%) is expressed by university graduates than people with lower education. There are clear differences in the level of trust in organizations working on the development and management of artificial intelligence. University researchers and the US military are the most trusted-50\% and $49 \%$. As for the impact of high-level machine intelligence on society, $22 \%$ of respondents think that the technology will be "on balance bad", $12 \%$ think that it would be "extremely bad" (possibility of human extinction), $21 \%$ think it will be "on balance good", and 5\% think it will be "extremely good." The results of a survey from 2019 are presented in Figure 10. 


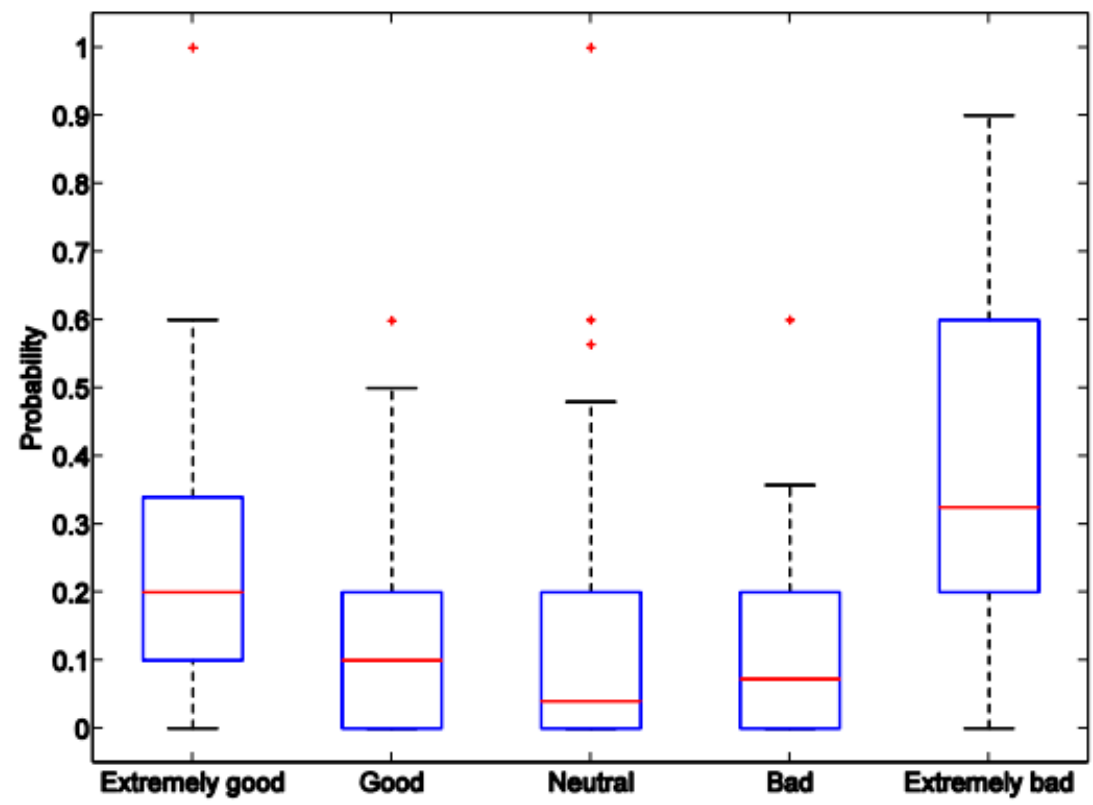

Figure 9. The results of the 2011 survey [78].

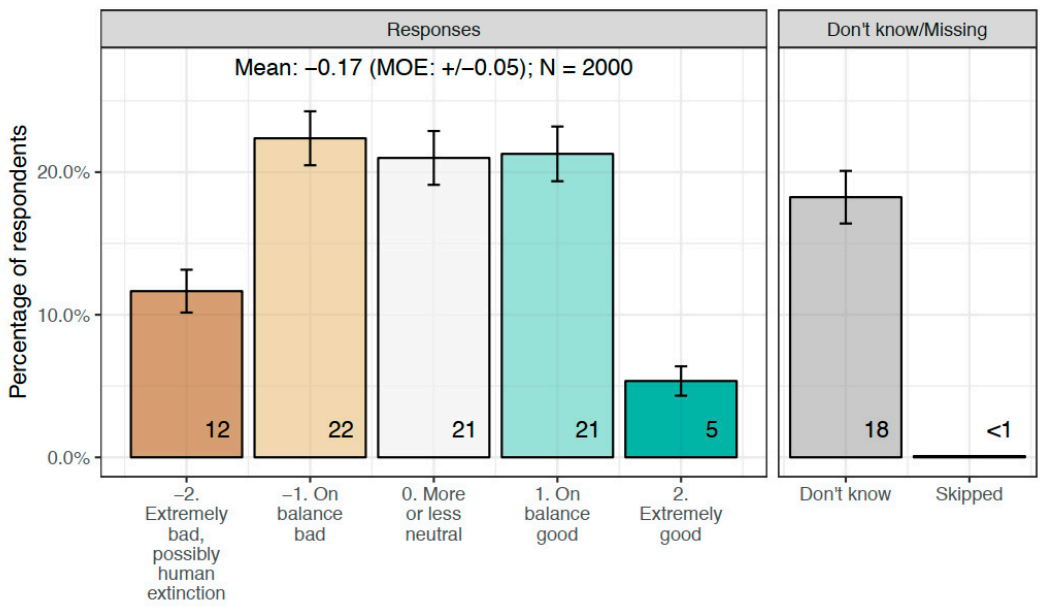

Figure 10. The results of the 2019 survey [79].

As research shows, according to society, military applications are among the main ones responsible for the development of $\mathrm{AI}$, at the same time enjoying great public trust. A positive trend is also the declining percentage of society predicting "extremely bad" impact of AI on humanity.

\subsection{Cooperation with Robots}

When the average person thinks about artificial intelligence, he has a vision of an intelligent robot performing typical human activities. A robot is a programmable machine which, in accordance with ISO 8373, to some extent autonomously performs the assigned tasks based on the given state-without human intervention [80]. The increasingly popular social robots $[81,82]$ are a specific type of robots. Social robots are defined as autonomous or semi-autonomous robots which, when communicating and interacting with people, behave in accordance with accepted social and behavioral norms adopted by people [83]. How do machines know what behavior people expect from them?

In [84], the authors propose an interesting way of learning ethical behavior by robots using data from social media (Twitter, Facebook, Instagram), records of court cases, and related available data sources. The training data set should include both ethical and 
unethical patterns of behavior. The first phase of training also involves the presence of a human trainer who would supervise and provide feedback to teach the machine the appropriate behavior in each scenario.

However, the continuous improvement of social robots causes public concern. People worry that in the near future robots can replace them at work and significantly increase unemployment. However, as the authors write in [85], "this perception implicitly overestimates the social skills of the robots, which despite being continually upgraded, are still far from being able to dominate humans entirely". The authors in [86] presented a proposal on how to bring man and machine closer together and increase people's trust in the machines with which they must cooperate. Pilot studies were conducted at the United States Air Force Academy to show that building a human relationship with an AI agent earlier can be beneficial for military missions. In the cases of building relationships, the robot asked people questions about their favorite food, type of music, while in cases without building relationships, the robot was only simply introduced to people. The participants felt much more comfortable with the robot if a relationship had been established beforehand.

\subsection{Ethics}

In addition to trust, another important problem with artificial intelligence is machine ethics, especially in military applications. People were afraid that the thinking machines could harm them and thought about moral status of the machines themselves. Time of war often requires morally difficult decisions from commanders. By definition, neural networks applications should rely only on logic and programmed algorithms without any emotions. However, in the case of military operations, logic and efficiency cannot be the sole determinant. Ethics in the context of military operations was discussed extensively by Helen Frowe in [87], which also touches on the topic of remote warfare.

The authors in [88] raise the important issue of Lethal Autonomous Weapon Systems (LAWS) and strive to answer the question of why artificial intelligence systems should not have the right to decide about killing people as part of warfare. The main problem the authors point to is the lack of perfect, non-error-making AI systems. In the case of deciding about human life, even the accuracy at the level of $99 \%$ is too small. Another issue is interpretability. Some decisions made by the algorithm are incomprehensible to people, which resulted in the introduction of the so-called "right to explanation" meaning a right to be given an explanation for an output of the algorithm [89].

People are afraid of what enemy army can do them and what their army can do civilian from other countries. Therefore, the Pentagon announced it has adopted "ethical principles" for AI in warfare in February 2020 [90]. Decisions made by automata should also be "traceable" and "governable." This means the possibility of deactivation systems that behavior raises concerns or threatens. Earlier the guideline included only an obligation of involving people in all AI military decisions. The actions of the Pentagon can be due to Google's resignation from renewing contract called "Project Maven" under pressure from employees [91,92].

\subsection{Consequences of Errors}

As it was written in the previous subsection, people are afraid that a malfunctioning algorithm may harm them. What about the consequences of such an error? When people make mistakes, it is easy to decide who is responsible for this situation. But when the machine makes a mistake, a situation is a bit more sophisticated. Who is to blame?

The main problem is the definition of mistake. Suppose a hypothetical situation that we are planning an elegant party. Our artificial intelligent system has developed a menu that has many dishes from very fashionable fusion cuisine, but we like traditional meals and are not satisfied with the choice of machine. Has the system made an error? Is the creator guilty of not having programmed our preferences in the machine algorithm? Maybe it is our fault because we did not control the machine during the menu selection process. This situation does not have very serious consequences in contrast to military decisions, 
e.g., regarding armed attacks, but it perfectly illustrates the problem of responsibility for errors made by artificial intelligence systems. The use of "ethical principles" can help, but every situation is different, and every person has a different moral system, so people are not ready to totally trust "intelligent systems" especially in state defense sector. They may be afraid that nobody will be responsible for any mistakes made.

In general, artificial intelligence is programmed to do useful tasks and help people, but malfunction can cause a very serious errors. The author in [93] tried to explain this correlation by using dynamic programing (division of the problem to be solved into subproblems with regard to several parameters [94]). The article analyzed which elements of the AI system can be causes of errors and disastrous consequences and tried to answer the question of when AI can be dangerous.

\section{Conclusions}

The aim of the submission was to present main areas of use of AI algorithms in the military sector, especially in objects detection, cybersecurity, robotics and logistic and discuss their impact on people's sense of security. The article shortly describes well-known algorithms of neural networks but in new, atypical applications. The authors wanted to point to the huge popularity of neural networks, which is increasing day by day thanks to the possibility of using big databases in the learning process. This applies both to commercial, research, educational and pure entertainment applications. The popularity of programs, such as AIE, shows how important this field of knowledge is. As research shows, people are still afraid of the possible effects of these technologies. This is understandable because even experts do not have a clear opinion on the future and development of artificial intelligence. As Prof. Stephen Hawking said: "The rise of powerful AI will be either the best, or the worst thing, ever to happen to humanity".

Author Contributions: M.B. contributed to theoretical formulation, design methodology, dataset development, original draft preparation and revision. The other author, Z.P., contributed to project supervision, theoretical formulation and revision of the initial draft. All authors have read and agreed to the published version of the manuscript.

Funding: This research work was supported and funded by The National Centre for Research and Development, grant no. CyberSecIdent/381319/II/NCBR/2018.

Conflicts of Interest: The authors declare no conflict of interest.

\section{References}

1. Definition of the Term 'Military Capability' Per Official Documentation of the United States Department of Defense. Available online: https:/ / www.militaryfactory.com/dictionary/military-terms-defined.asp?term_id=3357 (accessed on 25 January 2021).

2. Cyber Attack Trends: 2020 Mid-Year Report. Available online: https://research.checkpoint.com/2020/cyber-attack-trends-2020 -mid-year-report/ (accessed on 25 January 2021).

3. Wong, Y.H.; Yurchak, J.; Button, R.W.; Frank, A.; Laird, B.; Osoba, O.A.; Steeb, R.; Harris, B.N.; Bae, S.J. Deterrence in the Age of Thinking Machines; RAND Corporation: Santa Monica, CA, USA, 2020. [CrossRef]

4. Johnson, J. Artificial Intelligence \& Future Warfare: Implications for International Security. Def. Secur. Anal. 2019, 35, 147-169. [CrossRef]

5. Big Data Is Too Big Without AI-Maryville University Online. Available online: https://online.maryville.edu/blog/big-data-istoo-big-without-ai/ (accessed on 25 January 2021).

6. Zhu, S.; Cao, R.; Yu, K. Dual Learning for Semi-Supervised Natural Language Understanding. IEEE/ACM Trans. Audio Speech Lang. Process. 2020, 28, 1936-1947. [CrossRef]

7. Deshmukh, P.S. Travel Time Prediction using Neural Networks: A Literature Review. In Proceedings of the 2018 International Conference on Information, Communication, Engineering and Technology, Pune, India, 29-31 August 2018; pp. 1-5. [CrossRef]

8. Dogru, N.; Subasi, A. Traffic accident detection using random forest classifier. In Proceedings of the 201815 th Learning and Technology Conference (L\&T), Jeddah, Saudi Arabia, 25-26 February 2018; pp. 40-45. [CrossRef]

9. Berkhahn, S.; Neuwaeiler, I.; Fuchs, L. Real-Time Water Level Prediction Based on Artificial Neural Networks. In New Trends in Urban Drainage Modelling; Mannina, G., Ed.; UDM 2018. Green Energy and Technology; Springer: Cham, Switzerland, 2018; pp. 603-607. [CrossRef]

10. Ghorbani, M.A.; Deo, R.C.; Karimi, V.; Yaseen, Z.M.; Terzi, O. Implementation of a hybrid MLP-FFA model for water level prediction of Lake Egirdir, Turkey. In Stoch Environ Res Risk Assess; Springer: Heidelberg, Germany, 2018; Volume 32, pp. 1683-1697. [CrossRef] 
11. Williams, D.P. Underwater target classification in synthetic aperture sonar imagery using deep convolutional neural networks. In Proceedings of the 2016 23rd International Conference on Pattern Recognition (ICPR), Cancun, Mexico, 4-8 December 2016; pp. 2497-2502. [CrossRef]

12. Madichetty, S.; Sridevi, M. Detecting Informative Tweets during Disaster using Deep Neural Networks. In Proceedings of the 2019 11th International Conference on Communication Systems \& Networks (COMSNETS), Bengaluru, India, 7-11 January 2019; pp. 709-713. [CrossRef]

13. Ranjit, S.; Shrestha, S.; Subedi, S.; Shakya, S. Foreign Rate Exchange Prediction Using Neural Network and Sentiment Analysis. In Proceedings of the 2018 International Conference on Advances in Computing, Communication Control and Networking (ICACCCN), Greater Noida (UP), India, 12-13 October 2018; pp. 1173-1177. [CrossRef]

14. Varma, A.; Sarma, A.; Doshi, S.; Nair, R. House Price Prediction Using Machine Learning and Neural Networks. In Proceedings of the 2018 Second International Conference on Inventive Communication and Computational Technologies (ICICCT), Coimbatore, India, 20-21 April 2018; pp. 1936-1939. [CrossRef]

15. Lotfidereshgi, R.; Gournay, P. Speech Prediction Using an Adaptive Recurrent Neural Network with Application to Packet Loss Concealment. In Proceedings of the 2018 IEEE International Conference on Acoustics, Speech and Signal Processing (ICASSP), Calgary, AB, Canada, 15-20 April 2018; pp. 5394-5398. [CrossRef]

16. Pietrow, D.; Matuszewski, J. Objects detection and recognition system using artificial neural networks and drones. In Proceedings of the 2017 Signal Processing Symposium (SPSympo), Jachranka, Poland, 12-14 September 2017; pp. 1-5. [CrossRef]

17. Yanke, G. Tying the knot with a robot: Legal and philosophical foundations for human-artificial intelligence matrimony. Ai Soc. 2020. [CrossRef]

18. Floridi, L.; Cowls, J.; Beltrametti, M.; Chatila, R.; Chazerand, P.; Dignum, V.; Luetge, C.; Madelin, R.; Pagallo, U.; Rossi, F.; et al. AI4People-An Ethical Framework for a Good AI Society: Opportunities, Risks, Principles, and Recommendations. Minds Mach. 2018, 28, 689-707. [CrossRef] [PubMed]

19. Laufer, R. The social acceptability of AI systems: Legitimacy, epistemology and marketing. Ai Soc. 1992, 6, 197-220. [CrossRef]

20. Svenmarck, P.; Luotsinen, L.; Nilsson, M.; Schubert, J. Possibilities and Challenges for Artificial Intelligence in Military Applications. In Proceedings of the NATO Big Data and Artificial Intelligence for Military Decision Making Specialists' Meeting, Bordeaux, France, 31 May 2018.

21. DARPA-Accelerating the Exploration of Promising Artificial Intelligence Concepts. Available online: https://www.darpa.mil/ news-events/2018-07-20a (accessed on 25 January 2021).

22. Sanchez, S.L. Artificial Intelligence (AI) Enabled Cyber Defence. Available online: https://www.eda.europa.eu/webzine/issue1 4/cover-story / artificial-intelligence-(ai)-enabled-cyber-defence (accessed on 25 January 2021).

23. EMSA-European Maritime Safety Agency. Available online: http:/ / www.emsa.europa.eu/ (accessed on 25 January 2021).

24. Rhodes, B.J.; Bomberger, N.A.; Seibert, M.; Waxman, A.M. Maritime situation monitoring and awareness using learning mechanisms. In Proceedings of the MILCOM 2005-2005 IEEE Military Communications Conference, Atlantic City, NJ, USA, 17-20 October 2005; pp. 646-652. [CrossRef]

25. Al Salam, M. Adaptive Resonance Theory Neural Networks. Available online: https://www.academia.edu/38067953/Adaptive_ Resonance_Theory_Neural_Networks (accessed on 25 January 2021).

26. Mao, Z.; Massaquoi, S.G. Dynamics of Winner-Take-All Competition in Recurrent Neural Networks with Lateral Inhibition. IEEE Trans. Neural Netw. 2007, 18, 55-69. [CrossRef]

27. Iphar, C.; Ray, C.; Napoli, A. Data integrity assessment for maritime anomaly detection. Expert Syst. Appl. 2020, 147. [CrossRef]

28. Laxhammar, R. Anomaly detection for sea surveillance. In Proceedings of the 2008 11th International Conference on Information Fusion, Cologne, Germany, 30 June-3 July 2008; pp. 1-8.

29. Walck, C. Hand-Book on Statistical Distributions for Experimentalists; Universitet Stockholms: Stockholm, Swede, 2007 ; p. 119.

30. GeeksforGeeks-Gaussian Mixture Model. Available online: https://www.geeksforgeeks.org/gaussian-mixture-model/ (accessed on 25 January 2021).

31. Grefl, K.; van Steenkiste, S.; Schmidhuber, J. Neural Expectation Maximization. In Proceedings of the 31st International Conference on Neural Information Processing Systems, Hong Kong, China, 4-9 December 2017; pp. 6694-6704. [CrossRef]

32. Pu, W. Shuffle GAN With Autoencoder: A Deep Learning Approach to Separate Moving and Stationary Targets in SAR Imagery. IEEE Trans. Neural Netw. Learn. Syst. 2021, 1-15. [CrossRef]

33. Goodfellow, I.; Pouget-Abadie, J.; Mirza, M.; Xu, B.; Warde-Farley, D.; Ozair, S.; Courville, A.; Bengio, Y. Generative Adversarial Networks. Adv. Neural Inf. Process. Syst. 2014, 3. [CrossRef]

34. Dunn, J.C. A Fuzzy Relative of the ISODATA Process and Its Use in Detecting Compact Well-Separated Clusters. J. Cybern. 1973, 3, 32-57. [CrossRef]

35. Forgy, E.W. Cluster analysis of multivariate data: Efficiency versus interpretability of classifications. Biometrics 1965, 21, 768-769.

36. Fei, C.; Honghui, C.; Jianwei, M. Man-made Object Detection Based on Texture Clustering and Geometric Structure Feature Extracting. Int. J. Inf. Technol. Comput. Sci. (Ijitcs) 2011, 3, 9-16. [CrossRef]

37. The Future of Mine Countermeasures. Available online: https://fas.org/man/dod-101/sys/ship/weaps/docs/mcmfuture.htm (accessed on 25 January 2021).

38. THALES. The Future of Mine Warfare: A Quicker, Safer Approach. Available online: https://www.thalesgroup.com/en/unitedkingdom/news/future-mine-warfare-quicker-safer-approach (accessed on 25 January 2021). 
39. MBARI-Autonomous Underwater Vehicles. Available online: https://www.mbari.org/at-sea/vehicles/autonomousunderwater-vehicles / (accessed on 25 January 2021).

40. Song, Y.; Zhu, Y.; Li, G.; Feng, C.; He, B.; Yan, T. Side scan sonar segmentation using deep convolutional neural network. In Proceedings of the OCEANS 2017-Anchorage, Anchorage, AK, USA, 18-21 September 2017; IEEE: Piscataway, NJ, USA, 2017; pp. 1-4.

41. Zieliński, T.P. Cyfrowe Przetwar\#Zanie syg\#Nałów. Od teo\#rii do Zasto\#Sowań; Wydawnictwo Komunikacji i Łaczności: Warszawa, Poland, 2004; pp. 17-21.

42. Song, S.; Liu, J.; Guo, J.; Wang, J.; Xie, Y.; Cui, J.H. Neural-Network-Based AUV Navigation for Fast-Changing Environments. IEEE Internet Things J. 2020, 7, 9773-9783. [CrossRef]

43. Center for Strategies \& International Studies-Significant Cyber Incidents. Available online: https://www.csis.org/programs/ technology-policy-program/significant-cyber-incidents (accessed on 25 January 2021).

44. Pratt, M.K. What Is an Intrusion Detection System? How an IDS Spots Threats. Available online: https:/ / www.csoonline.com/ article/3255632/what-is-an-intrusion-detection-system-how-an-ids-spots-threats.html (accessed on 25 January 2021).

45. Ghanem, K.; Aparicio-Navarro, F.J.; Kyriakopoulos, K.G.; Lambotharan, S.; Chambers, J.A. Support Vector Machine for Network Intrusion and Cyber-Attack Detection. In Proceedings of the 2017 Sensor Signal Processing for Defence Conference (SSPD), London, UK, 6-7 December 2017; pp. 1-5. [CrossRef]

46. Kowalczyk, A. Support Vector Machines; Syncfusion: Research Triangle, NC, USA, 2017; pp. 25-26.

47. Ososwski, S. Neural Networks for Information Processing, 4th ed.; Oficyna Wydawnicza Politechniki Warszawskiej: Warsaw, Poland, 2020; pp. 193-194. ISBN 978-83-7814-923-1.

48. Shah, A.; Clachar, S.; Minimair, M.; Cook, D. Building Multiclass Classification Baselines for Anomaly-Based Network Intrusion Detection Systems. In Proceedings of the 2020 IEEE 7th International Conference on Data Science and Advanced Analytics (DSAA), Sydney, Australia, 6-9 October 2020; pp. 759-760. [CrossRef]

49. Ruder, S. An overview of gradient descent optimization algorithms. arXiv 2017, arXiv:1609.04747v2.

50. FAQs about Boston Dynamics. Available online: https://www.bostondynamics.com/about (accessed on 25 January 2021).

51. Guizzo, E. By Leaps and Bounds: An exclusive look at how Boston dynamics is redefining robot agility. IEEE Spectr. 2019, 56, 34-39. [CrossRef]

52. Loesch, A.; Bourgeois, S.; Gay-Bellile, V.; Gomez, O.; Dhome, M. Localization of 3D objects using model-constrained SLAM. Mach. Vis. Appl. 2018, 29, 1041-1068. [CrossRef]

53. Ding, Z.; Huang, R.; Hu, B. Robust Indoor SLAM based on Pedestrian Recognition by Using RGB-D Camera. In Proceedings of the 532019 Chinese Automation Congress (CAC), Hangzhou, China, 22-24 November 2019; pp. 292-297. [CrossRef]

54. Rizk, M.; Mroue, A.; Farran, M.; Charara, I. Real-Time SLAM Based on Image Stitching for Autonomous Navigation of UAVs in GNSS-Denied Regions. In Proceedings of the 2020 2nd IEEE International Conference on Artificial Intelligence Circuits and Systems (AICAS), Genova, Italy, 31 August-2 September 2020; pp. 301-304. [CrossRef]

55. ROBOTS-Your Guide to the World of Robotics. Available online: https:/ / robots.ieee.org/ (accessed on 25 January 2021).

56. Hiejima, T.; Kawashima, S.; Ke, M.; Kawahara, T. Effectiveness of Synchronization and Cooperative Behavior of Multiple Robots based on Swarm AI. 2019 IEEE Asia Pacific Conference on Circuits and Systems (APCCAS), Bangkok, Thailand, 11-14 November 2019; pp. 341-344. [CrossRef]

57. Campbell, D.; Roth, J. The Logistics of the Roman Army at War (264 B.C.-A.D. 235). J. Rom. Stud. 2000, 90, 224. [CrossRef]

58. Wang, J.; Cao, L.; Shen, Y.; Zheng, G. Research on Design of Military Logistics Support System Based on IoT. In Proceedings of the 2018 Prognostics and System Health Management Conference (PHM-Chongqing), Chongqing, China, 26-28 October 2018; pp. 829-832. [CrossRef]

59. Sobb, T.M.; Turnbull, B. Assessment of Cyber Security Implications of New Technology Integrations into Military Supply Chains. In Proceedings of the 2020 IEEE Security and Privacy Workshops (SPW), San Francisco, CA, USA, 21-21 May 2020; pp. 128-135. [CrossRef]

60. Kim, H.M.; Laskowski, M. Toward an ontology—driven blockchain design for supply—chain provenance. Intell. Syst. Account. Financ. Manag. 2018, 25, 18-27. [CrossRef]

61. Tortonesi, M.; Morelli, A.; Govoni, M.; Michaelis, J.; Suri, N.; Stefanelli, C.; Russell, S. Leveraging Internet of Things within the military network environment-Challenges and solutions. In Proceedings of the 2016 IEEE 3rd World Forum on Internet of Things (WF-IoT), Reston, VA, USA, 12-14 December 2016; pp. 111-116. [CrossRef]

62. Wang, W.; Guan, Y.; Jiang, D.; Yao, P. Analysis of information flow control in military supply chain management. In Proceedings of the 2010 8th International Conference on Supply Chain Management and Information, Hong Kong, China, 6-9 October 2010; pp. 1-4.

63. Yin, C.; Yang, R.; Zou, X. Research of Command Entity Intelligent Decision Model based on Deep Reinforcement Learning. In Proceedings of the 2018 5th IEEE International Conference on Cloud Computing and Intelligence Systems (CCIS), Nanjing, China, 23-25 November 2018; pp. 552-556. [CrossRef]

64. Lapan, M. Deep Reinforcement Learning Hands-on: Apply Modern RL Methods to Practical Problems of Chatbots, Robotics, Discrete Optimization, Web Automation, and More; Packt Publishing Ltd.: Birmingham, UK, 2020, ISBN 978-1-83882-004-6. 
65. Ajakwe, S.O.; Nwakanma, C.I.; Lee, J.M.; Kim, D.S. Machine Learning Algorithm for Intelligent Prediction for Military Logistics and Planning. In Proceedings of the 2020 International Conference on Information and Communication Technology Convergence (ICTC), Jeju, Korea (South), 21-23 October 2020; pp. 417-419. [CrossRef]

66. Charles River Analitics. Available online: https://www.cra.com/ (accessed on 25 January 2021).

67. Tactical Combat Casualty Care Handbook Lessons and Best Practices; Version 5; Center for Army Lessons Learned: Fort Leavenworth, KS, USA, 2017; pp. 13-17.

68. European Defence Agency—Big Data Analytics for Defense. Available online: https:/ / eda.europa.eu/webzine/issue14/coverstory / big-data-analytics-for-defence (accessed on 16 March 2021).

69. Xiang, Z.; Xiaofang, L.; Weigang, G. Analysis of the Application of Military Big Data in Equipment Quality Information Management. In Proceedings of the 2019 IEEE 4th International Conference on Cloud Computing and Big Data Analysis (ICCCBDA), Chengdu, China, 12-15 April 2019; pp. 68-71. [CrossRef]

70. Liu, M.; Ma, J.; Jin, L. Analysis of Military Academy Smart Campus Based on Big Data. In Proceedings of the 201810 th International Conference on Intelligent Human-Machine Systems and Cybernetics (IHMSC), Hangzhou, China, 25-26 August 2018; pp. 105-108. [CrossRef]

71. Weitz, R. PLA Military Reforms: Defense Power with Chinese Characteristics. Available online: https: / / www.worldpoliticsreview. com/articles/18215/pla-military-reforms-defense-power-with-chinese-characteristics (accessed on 16 March 2021).

72. Petit, H. Could Russia's President One Day be a ROBOT? Alisa AI Software that Claims 'Enemies of the People will be Shot' wins the Backing of 40,000 to Stand against Vladimir Putin. Available online: https: / / www.dailymail.co.uk/sciencetech/article-5166 847 / Russian-AI-Alisa-wins-backing-40--000-election-run-up.html (accessed on 25 January 2021).

73. Meet Your Politician of the Future. Available online: http://www.politiciansam.nz/ (accessed on 25 January 2021).

74. Arrieta, A.B.; Díaz-Rodríguez, N.; Del Se, J.; Benneto, A.; Tabik, S.; Barbado, A.; Garcia, S.; Gil-Lopez, S.; Molina, D.; Benjamins, R.; et al. Explainable Artificial Intelligence (XAI): Concepts, taxonomies, opportunities and challenges toward responsible AI. Inf. Fusion 2020, 58, 82-115. [CrossRef]

75. Luotsinen, L.; Oskarsson, D.; Svenmarck, P.; Wickenberg, B.U. Explainable Artificial Intelligence: Exploring XAI Techniques in Military Deep Learning Applications. Available online: https://www.foi.se/report-summary?reportNo=FOI-R--4849--SE (accessed on 25 January 2021).

76. Adadi, A.; Berrada, M. Peeking Inside the Black-Box: A Survey on Explainable Artificial Intelligence (XAI). IEEE Accesss 2020, 6, 52138-52160. [CrossRef]

77. Centre for the Governance of AI. Available online: https://www.fhi.ox.ac.uk/GovAI (accessed on 22 January 2021).

78. Sandberg, A.; Bostrom, N. Machine Intelligence Survey. In Technical Report 2011-1; Future of Humanity Institute, Oxford University: Oxford, UK, 2011; pp. 1-12.

79. Zhang, B.; Dafoe, A. Artificial Intelligence: American Attitudes and Trends; Center for the Governance of AI, Future of Humanity Institute, University of Oxford: Oxford, UK, 2019; Available online: https:/ / papers.ssrn.com/sol3/papers.cfm?abstract_id=3312 874 (accessed on 25 January 2021).

80. International Federation of Robotics. Available online: http:/ /www.ifr.org/service-robots (accessed on 22 January 2021).

81. Onyeulo, E.B.; Gandhi, V. What Makes a Social Robot Good at Interacting with Humans? Information 2020, 11, 43. [CrossRef]

82. Lazzeri, N.; Mazzei, D.; Cominelli, L.; Cisternino, A.; De Rossi, D.E. Designing the Mind of a Social Robot. Appl. Sci. 2018, 8, 302. [CrossRef]

83. Bartneck, C.; Nomura, T.; Kanda, T.; Suzuki, T.; Kennsuke, K. A cross-cultural study on attitudes towards robots. In Proceedings of the HCI International, Las Vegas, NV, USA, 22-27 July 2005. [CrossRef]

84. Buenfil, J.; Arnold, R.; Abruzzo, B.; Korpela, C. Artificial Intelligence Ethics: Governance through Social Media. In Proceedings of the 2019 IEEE International Symposium on Technologies for Homeland Security (HST), Woburn, MA, USA, 5-6 November 2019; pp. 1-6. [CrossRef]

85. Van Greunen, D. User Experience for Social Human-Robot Interactions. In Proceedings of the 2019 Amity International Conference on Artificial Intelligence (AICAI), Dubai, United Arab Emirates, 4-6 February 2019; pp. 32-36. [CrossRef]

86. Bellas, A.; Perrin, S.; Malone, B.; Rogers, K.; Lucas, G.; Phillips, E.; Tossel, C.; de Visser, E. Rapport Building with Social Robots as a Method for Improving Mission Debriefing in Human-Robot Teams. In Proceedings of the 2020 Systems and Information Engineering Design Symposium (SIEDS), Charlottesville, VA, USA, 24 April 2020; pp. 160-163. [CrossRef]

87. Frowe, H. The Ethics of War and Peace: An. Introduction, 2nd ed.; Routledge: London, UK, 2015. [CrossRef]

88. Šimák, V.; Gregor, M.; Hruboš, M.; Nemec, D.; Hrbček, J. Why Lethal autonomous weapon systems are unacceptable. In Proceedings of the 2017 IEEE 15th International Symposium on Applied Machine Intelligence and Informatics (SAMI), Herl'any, Slovakia, 26-28 January 2017; pp. 359-364. [CrossRef]

89. De La Torre, L.F. The 'Right to an Explanation' under EU Data Protection Law. Available online: https://medium.com/goldendata/what-rights-related-to-automated-decision-making-do-individuals-have-under-eu-data-protection-law-76f70370fcd0 (accessed on 25 January 2021).

90. Mind for Minds-US military Adopts 'Ethical' AI guidelines. Available online: https://www.dw.com/en/us-military-adoptsethical-ai-guidelines / a-52517260 (accessed on 25 January 2021).

91. Google's Departure from Project Maven Was a 'Little Bit of a Canary in a Coal Mine'. Available online: https:/ /www.fedscoop. com/google-project-maven-canary-coal-mine/ (accessed on 18 March 2021). 
92. Artificial Intelligence (AI) Becomes the Latest Arms Race as Adversaries Seek to Perfect Machine Learning. Available online: https://www.militaryaerospace.com/computers/article/14189468/artificial-intelligence-ai-project-maven-arms-race (accessed on 18 March 2021).

93. Mathew, A. The Peril of Artificial Intelligence. In Proceedings of the 2020 Fourth International Conference on Inventive Systems and Control (ICISC), Coimbatore, India, 8-10 January 2020; pp. 919-924. [CrossRef]

94. Bellman, R. On the Theory of Dynamic Programming. In Proceedings of the National Academy of Sciences (USA), Santa Monica, CA, USA, 1 August 1952. 